\title{
Chapter 7 \\ Agricultural Research and Extension Linkages in the Amhara Region, Ethiopia
}

\author{
Tilaye Teklewold Deneke and Daniel Gulti
}

\begin{abstract}
Agricultural innovation systems require strong linkage between research and extension organizations in particular, and among the various actors engaged in the agricultural sector in general. In the context of Ethiopia and the Amhara regional state, the agricultural research and extension system is characterized by a large number of actors in a fragmented and underdeveloped innovation system, resulting in very low national and regional innovation capacities. Farmers are generally viewed as passive recipients of technology. As a result, research outputs do not reach farmers and remain shelved in research centers. Instead, research and extension need to take place within interlinked, overlapping and iterative processes. This chapter reviews past initiatives to bring about integration among these actors to identify areas for improvement.
\end{abstract}

Keywords Research • Extension services - Ethiopia - Innovation systems • Innovation capacities

\section{Introduction}

Agriculture in Ethiopia is the most important sector of the economy, contributing over $46.89 \%$ of GDP, employing about $80 \%$ of the labour force, and serving as the source of $60 \%$ of export earning (MoFED 2011). Due to this dominance, poverty, food security and the performance of the economy at large depends heavily on the performance of the agricultural sector. Though there are positive trends in recent years (during the first 5 year growth and transformation plan), the agricultural sector has grown by $6.6 \%$ per annum on average (MoFED 2015), the sector has largely remained underdeveloped, low input-low output and barely subsistent. The level of productivity of major crops, such as teff, sorghum, wheat and maize, has remained below 2 t/ha (see Fig. 7.1). The country has historically been chronically

T.T. Deneke (ه)

Amhara Agricultural Research Institute (ARARI), Bahir Dar, Ethiopia

e-mail: ttddeneke@yahoo.com

D. Gulti

Agricultural Transformation Agency (ATA), Addis Ababa, Ethiopia

(C) The Author(s) 2016

F.W. Gatzweiler, J. von Braun (eds.), Technological and Institutional Innovations for Marginalized Smallholders in Agricultural Development, DOI 10.1007/978-3-319-25718-1_7 


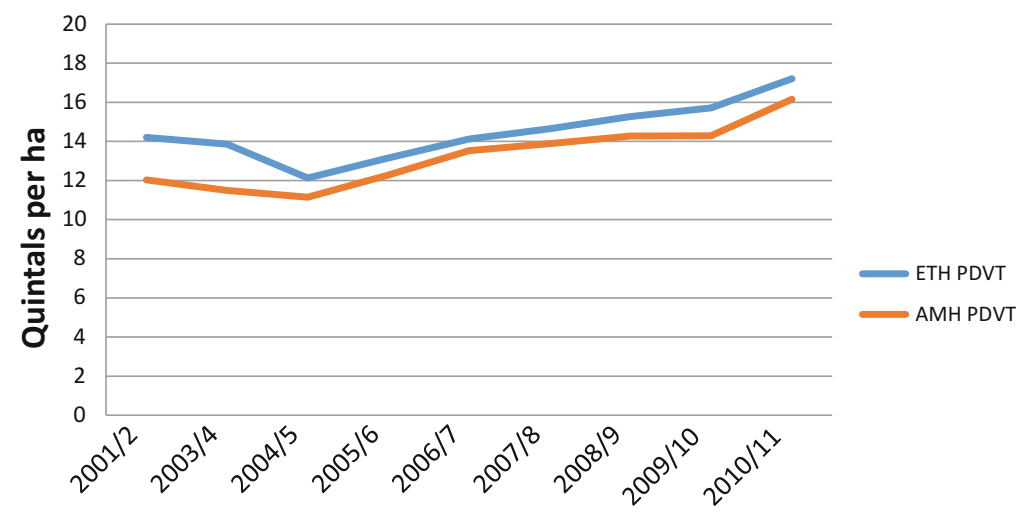

Fig. 7.1 Total grain productivity for the cropping years 2001/2-20010/11 for Ethiopia (ETH) and Amhara (AMH) (Source: Own analysis based on CSA data years 2001-2011)

food insecure and still depends on commercial imported food and food aid to some extent.

In order to avert this situation, the country followed a policy of using agricultural development as an engine of growth based on the justification that the sort of broadbased growth and rapid development that would lift the masses out of poverty in the shortest possible time lay in the agricultural sector. This was based on the fact that the vast majority of the population lives on agriculture and the country is endowed with abundant land and labour resources, although it is short in capital stocks. Over the last two decades, the GoE (Government of Ethiopia) has followed the pro-smallholder policy framework known as Agricultural Development Led Industrialization (ADLI). The policy is aimed at increasing the production and productivity of smallholder agriculture to insure household level food security and generating capital from export earnings of agricultural products, as well as paving the way for industrial development through supplying adequate, high quality and cheap raw material for agro-processing sectors. This meant increased government investment in agricultural research, extension service, improvement of rural infrastructure and the provision of support services such as credit, external input supply, and agricultural commodity marketing.

Provision of such support in a coordinated, effective and efficient manner has, however, been a great challenge, as these support services are given by a number of separate government offices and nongovernmental organizations without laying down a viable and efficient mechanism for coordination and linkage. This has resulted in sluggish technological change that can be verified by the fact that the percentage of farmers using improved agricultural technologies, such as fertilizers and high yielding varieties, has continued to be low (in the Amhara region, only $15 \%$ of the vast majority of agricultural technologies developed by the federal and regional agricultural research systems have been accessed and adopted by the farming community). 


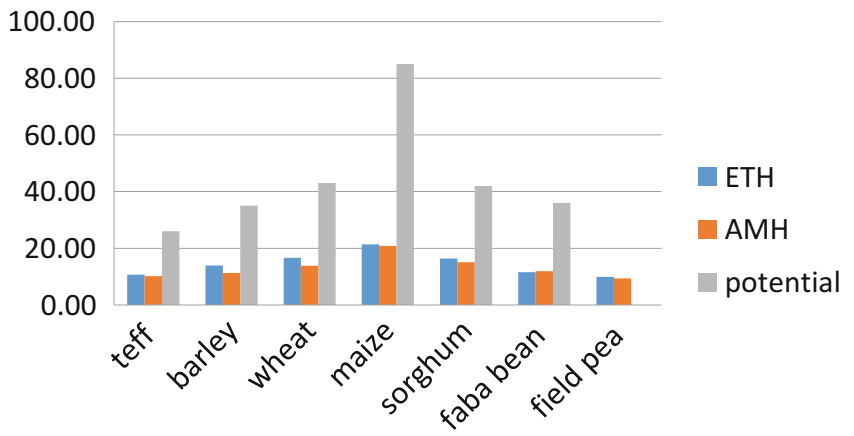

Fig. 7.2 Actual and Potential productivity of major crops in (quintals/ha) for Ethiopia (ETH) and Amhara (AMH) (Source: own analysis based on CSA data and data from the National Variety Register 2014)

Until 2014, over 960 high yielding varieties had been developed by the national agricultural research system, of which not less than 106 of them belong to ARARI. In addition to these, several improved agronomic practices, such as rate, method and time of fertilizer application, crop protection practices, seed rates and irrigation methods, have been recommended. Improved animal breeds, forage species, and feeding recommendations have also been developed. Soil and water conservation structures, and improved methods of managing problematic soils, such as acidic soils, saline soils and water logged heavy vertisols, have been tested and approved. Tree species suitable for farm forestry and agro forestry practices have been introduced, tested and adapted. Intermediate mechanization technologies and improved pre-harvest and post-harvest farm implements were also developed. Yet, average smallholder yields remain low (below $2 \mathrm{t} / \mathrm{ha}$ ) for major crops and yield gaps between research plots and the farmers' fields remained high (see Figs. 7.1 and 7.2).

This dismal situation can, to a great extent, be attributed to the weak link and lack of coordination and alignment between agricultural research and extension systems at all levels of government. All the necessary organizations and support services related to the generation of knowledge and technology, input delivery, advisory service, and marketing and credit services are in place. But these actors all function in a largely uncoordinated and fragmented manner.

According to Havelock (1986), cited in Kassa (2008), coordination or linkage symbolizes two systems connected by messages to form a greater system. Agricultural research and extension are examples of two systems that can be linked by information flow and feedback (Munyua et al. 2002). Setting up the institutional linkage to foster proper information flow and effective collaboration is the most serious institutional problem in developing research and extension programmes.

Over recent decades, the Ethiopian government has made various efforts to build the capacity of the research and extension systems and strengthen their linkages to improve adoption and productivity. The linkage between research and extension 
systems plays a significant role in the generation and dissemination of appropriate technologies. Strengthening research and extension linkages must mean cultivating greater and more effective interaction among the stakeholders in the agricultural sector. To this end, several linkage initiatives have been tried out at different times with different levels of effectiveness. This chapter serves as an overview of past efforts and the current status of linkage between agricultural research and extension, as well as among the whole range of actors involved in agricultural commodity value chains in Ethiopia, with a focus on the Amhara region. The next section deals with the various models of research and extension linkage which will serve as theoretical underpinnings. The third section will present an overview of past linkage initiatives in terms of their strengths, weaknesses and challenges. The fourth section will analyze the current status of linkage among actors involved in agricultural research and development in Ethiopia. The last section draws conclusions and lessons from the foregoing analysis.

\section{Research: Extension Linkage Models}

At least three generic types of linkage model can be identified. These are the linear, top-down model, which is commonly known as the transfer of technology or "ToT" model, the farming systems research (FSR) model and the Innovation Systems Model. These three models have their own historical backgrounds, distinct features and resulting implications and mechanisms for linkage between the agricultural research and extension systems in particular, and linkage among the various actors in the agricultural commodity value chains in general.

The "ToT" model was the prominent model in the 1960s and 1970s. It is characterized by the separation of technology production and application. In this model, researchers are knowledge generators, extension agents are expected to transfer the knowledge to farmers, and farmers are passive recipients. It is a 'topdown' one-way communication model with information and technology flowing from researchers to end users via extension agents like a conveyer belt (Kassa 2008). Research, extension and adoption were viewed not as interlinked and iterative processes but as separate and compartmentalized processes that can be organized in different specialized structures.

This model has worked very well in the industrialized agriculture of developed western countries, as well as in the Asian green revolution, where the farming systems are not complex, diverse and risk-prone like those of Ethopia and the rest of Sub-Saharan Africa. The training and visit approach, commonly known as T\&V, which has been instrumental in promoting the Asian green revolution technologies, was actually based on this model. The ToT model is still very much persistent in many countries, and people tend to think of the research and extension process as a separate and distinct process that can be linearly linked, despite the fact that it failed to deliver the intended rapid agricultural development through intensification in Sub-Saharan African counties that it had in the case of the Asian green revolution. 
In the 1980s, the recognition that farmers are capable of actively adapting and coming up with new ideas and solutions to local problems, rather than being passive recipients, led to the birth of the holistic approach and Farming Systems Research (FSR). This approach is also mainly based on the idea that the reasons behind the low level of adoption of agricultural technologies is related to the fact that conditions for farmers were different from those of research stations, and the technologies developed were hardly suitable for their conditions. In the FSR model, the focus was generally on on-farm client-oriented research (OFCOR) and ways of linking farmers directly with researchers. The general approach in this model was a process in which a multidisciplinary team of researchers and extensionists identify and rank problems and opportunities, suggest alternative solutions, initiate joint on-farm experimentation and disseminate the results.

In the 1990s, the realization that previous approaches had failed to recognize institutional constraints and the usefulness of multiple actors led to a shift in focus from "technology" to "innovation". In this model, institutions are emphasized as being the main bottlenecks, not technology. It also recognized that complex problems require solutions that come out of interactions between many actors. Hence, along with the traditional actors in the Agricultural Knowledge and Information System (AKIS), those actors outside the AKIS who were parts of the value chain were also included.

\section{History of Research and Extension Organizations and Linkage in Ethiopia}

In Ethiopia, formal research and extension service was started in 1952 when the Agricultural and Technical School at Jima and the College of Agriculture and Mechanical Arts were established. They were modeled after the US land grant university system, which emphasized the integration of education, research and extension. The extension mandate was later transferred to the Ministry of Agriculture. Later on, research was also divorced from education when the Institute of Agricultural Research (IAR) was established in 1966. By compartmentalizing research and extension activities, the linear R-E-F model was adopted. At that time, there was no mechanism set for the coordination of research and extension, and this marked the formal divorce of research and extension that has existed ever since.

At present, the Ethiopian agricultural research system is characterized by a decentralized research structure in which there are federal and regional research institutes composed of a number of research centers spread across the various agroecologies of the country. There are 69 agricultural research centers under the federal, regional and university research institutes. Until recently, there was no umbrella organization coordinating research in Ethiopia (currently, the Ethiopian Agricultural Research Council is being established, modeled after the Indian 
Council for Agricultural Research). The federal agricultural research institute known as the EIAR (Ethiopian Institute of Agricultural Research) itself is engaged in applied research not much different from what the regional institutes do and is not serving as a national agricultural research coordination or governing body. The relationship between the federal and region research institutes was largely competitive than collaborative. Structurally, the research institutes are under the Ministry or Bureaus of Agriculture, but they enjoy considerable autonomy and there is no direct reporting or accountability between the federal and region agricultural research institutes. However, there are, in fact, some collaborative research projects and voluntary research collaboration on some commodities.

The extension organization also has a decentralized structure that includes the federal ministry of agriculture, the regional bureau of agriculture, and the district (called Woreda in Amharic) offices of agriculture. There is such a huge army of extension personnel that there are three development agents (DAs) in every kebele (smallest administrative units). There is also one Farmers Training Center (FTC) in most of the kebeles.

Several attempts were made in the past to bring strong linkage, coordination, collaboration and efficient delivery of research and extension services to the farming community. The first attempt to address formal research, extension and farmer linkage was the establishment of the IAR/EPID (Institute of Agricultural Research Extension Project Implementation Department of MoA) on-farm research program in 1974. This joint program was mainly initiated for agricultural technology package testing and formulation of research recommendations for specific areas. The program was discontinued in 1977 due to budget problems. In 1980/ 81, the program was reinitiated with a new name, IAR/ADD (Agricultural Development Department). However, it too was not successful because it was poorly planned: there was no close monitoring of trial sites by researchers, extension personnel didn't know what the trials were about, and there was no feedback coming to the researchers. As a result, it was not possible to identify technologies suitable for immediate transfer to farmers.

Another linkage mechanism was designed in the early 1980s with the advent of Farming Systems Research (FSR). This focused on multidisciplinary surveys to identify production constraints, verify available technologies being used by farmers, and hand over those found to be superior. The main contributions of FSR research-extension linkage were providing feedback to researchers on the characteristics of technologies, providing researchers with information on farmers' problems, formulating recommendations appropriate to smallholder farmers, and generating useful recommendations for policymakers, but the program was expensive and time-consuming, and thus was phased out as project funds run out.

In 1985, following the lessons of FSR, and also mainly for the purpose of transferring technologies developed and shelved at IAR, IAR established the Research-Extension Division (RED). It was given the mandate of strengthening research-extension-farmer linkage by establishing and running the first formal linkage platform for research and extension, called the Research-Extension Liaison Committee (RELC). Since its establishment, the RED has played an important role 
in disseminating agricultural technologies, conducting demonstrations, providing training, and coordinating RELC linkage activities. Later on, in 2009, with the advent of Business Process Re-engineering (BPR), REDs were closed at most of the research institutes with the idea that they simply duplicated the work of extension departments of the Bureau of Agriculture (BoA). With the BPR, research and extension were viewed as separate processes which can be linked by a case team established in the BoA.

The Research-Extension Liason Committee was the first formal platform, established in 1986 at zonal and national levels to enhance vertical and horizontal integration of research and extension. RELC was primarily run by the REDs of IAR research centers. The primary role of zonal RELC was to review and approve research proposals and extension recommendations, identify training needs for SMSs, and oversee research-extension and farmer linkage in the respective zones of research centers. The national RELC was responsible for provision of overall policy direction and capacity building. Yet, RELC was largely ad hoc; meetings were not regular. It was also seriously affected by frequent changes in the organizational structure of MoA, resulting in discontinuities in many linkage arrangements and joint undertakings. Although the terms of reference of RELC stated that farmers were members of RELC, in practice, they were either passive participants or were not represented at all. It didn't have any legal status, which affected its decision-making power and institutionalizing accountability among members.

In the late 1990s, RELC was replaced by the Research-Extension-Farmers Linkage Advisory Council (REFAC). REFAC was organized at national, regional and research center levels. It was also run by the RED of the Ethiopian Agricultural Research Organization (EARO), funded by The World Bank's Agricultural Research and Training Project (ARTP). REFAC was responsible for the overall guidance of research and extension programs, and oversight of the linkage activities (FDRE 1999). The council had a chairperson and secretary. It had subcommittees or working groups, a women farmers group, representatives of farmers research groups, a resource management group and a farming systems group. Nevertheless, REFAC could not produce integration as expected due to the lack of commitment from stakeholders, the low involvement of certain key stakeholders and the fact that it was dominated by researchers. There was no frequent meeting of stakeholders and they met only once a year at all levels. The other serious problems in the REFAC was the lack of accountability of partners, i.e., failure to deliver on promises, and the fact that there was no clarity on the responsibility of actors.

\section{Current Mechanisms for Research and Extension Linkage}

In order to overcome the shortcomings of REFAC, a multi-stakeholder platform called the Agriculture and Rural Development Partners Linkage Advisory Council (ARDPLAC) was established in 2008. It is organized at national, regional, zonal 

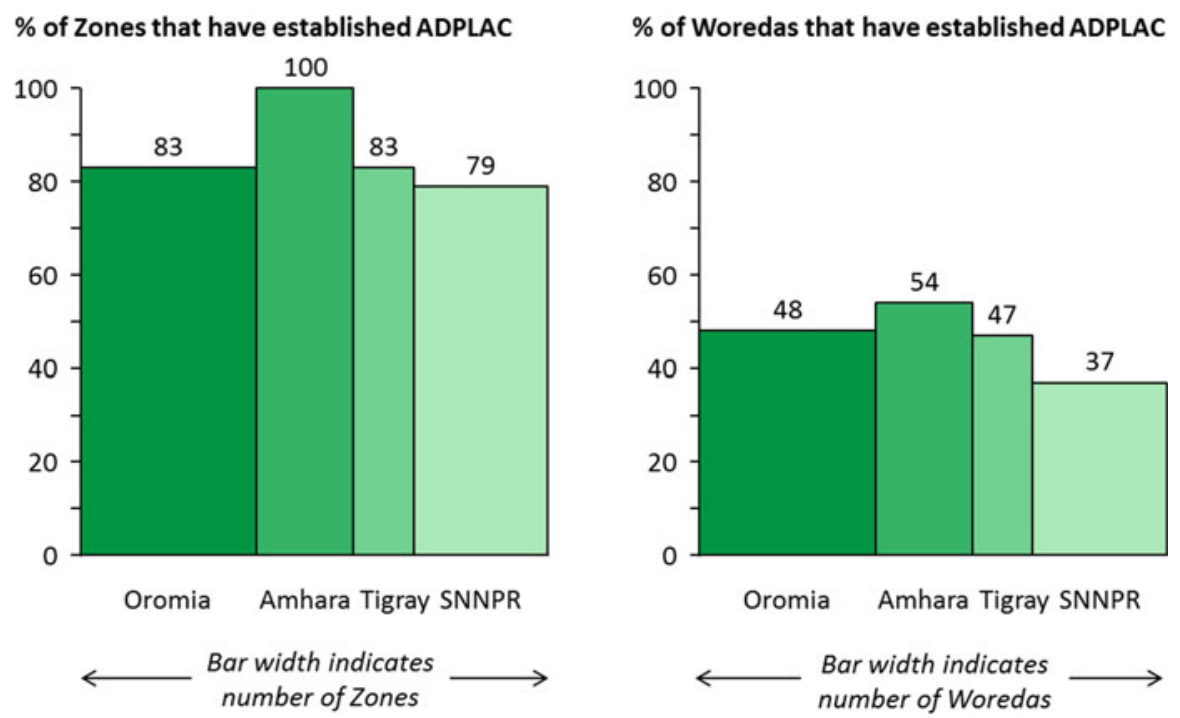

Fig. 7.3 Level of establishment of ADPLACs at Zonal and Woreda levels (Source: Communication with MoA- ADPLAC Expert 2012)

and district levels. In the Amhara Region, the council is institutionalized from the regional to the kebele levels, with its secretariat office being hosted at the Extension Process Service, under the Regional BoA. Unlike RELC and REFAC, ARDPLAC is coordinated by the Bureau of Agriculture or Ministry of Agriculture and, like its predecessors, is funded by World Bank projects. Later, the name was changed to the Agriculture Development Partners Linkage Advisory Council (ADPLAC) with the restructuring of the former Ministry of Agriculture and Rural Development into the Ministry of Agriculture, leaving all the rural development-related organizations, such as rural water service and rural roads authority, to stand on their own. Hence, these sectors are no longer part of the linkage platform, and only actors directly related to agriculture are included in the forum.

Structurally, ADPLACs are organized at national, regional, zonal, woreda and kebele levels that represent different levels of performance. Although ADPLACS are established in the majority of the zones, at the woreda level, there is still no ADPLAC in most of them (Fig. 7.3).

The current ADPLAC platforms, at all levels, face various systemic and operational challenges. First of all, like its predecessors, ADPLAC is not properly institutionalized at all levels. There are inadequate permanent staff and the platform is primarily supported by project money, rather than having permanent budget allocation. There is an ad-hoc nature to the planning and execution of linkage activities. And the platform lacks a long-term vision and strategy for systematically creating alignment across the various development actors for a greater impact. 
Moreover, due to the lack of ownership and loose engagement, leadership, decision-making, communication, passion for a shared vision, enforced roles and responsibilities, and learning and sharing are all sub-optimal among the stakeholders. There are no agreed-upon roles and responsibilities and enforcement mechanisms to ensure that assigned roles are performed. This is partly due to weak stakeholder coordination and engagement capacity at all levels, which led to low awareness and shared vision among development partners about the functions and mechanisms of stakeholder platforms. Moreover, the frequent reshuffling of institutional representatives has also led to poor knowledge preservation and transition and loss of institutional memory. Whenever there is an urgent task at the offices, ADPLAC experts are relieved from their linkage duties and take up other roles.

To have a very successful engagement platform that responds to the needs of the participants and addresses their problems, an efficient monitoring, learning and evaluation (MLE) mechanism plays a crucial role. However, the current ADPLAC platforms are characterized by poor or, in many cases, non-existent MLE. There is no mechanism that gauges and documents stakeholder perception about benefits gained by individual stakeholders from participating in the platform and the overall learning process.

The other ADPLAC challenge is the issue of representation, in terms of both relevance and inclusiveness. Currently, membership is unmanageable and not really effective. It is important to include only relevant members to make ADPLACs effective. At present ADPLACs lack relevant and influential members, including those from the private sector, to make the platform inclusive and forwardlooking. Additionally, all the stakeholders also lack commitment to the cause of ADPLAC.

Currently, the government is driving ADPLAC platforms at all levels and the participation of the private sector is very low. And apart from participating in regular meetings, there is no shared long-term vision of success among the stakeholders. Moreover, it is not very clear what do the ADPLACs aspire to achieve in the long-run? What will change as the result of the ADPLAC's activities? What are the core functions of the ADPLAC? What are the key performance indicators? How will the ADPLAC influence the overall modernization of agricultural advisory service systems?

In addition, role- and responsibility-sharing and tracking, as well as reporting among the members, are not attached to accountability. If all the stakeholders are convinced of the benefits of participating in the platform, then they can start to assume responsibility in assigning tasks to the right stakeholders and tracking their accomplishments and impact.

Although ADPLAC is more extensive and inclusive than its predecessors, its outreach to the woreda and kebele levels is rather limited. Awareness and effectiveness of ADPLAC decreases down the administrative ladder, starting at the regional level. There are three key reasons for this.

According to Demekech et al. (2010), the effectiveness of the ADPLAC challenged by poor abundance and weak strength of linkages, low awareness about what ADPLAC is among actors and poor facilitation for linkage creation. As can be seen 
Links not existing or weak

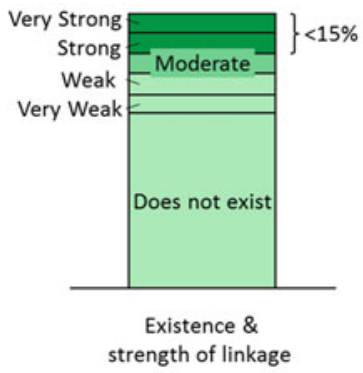

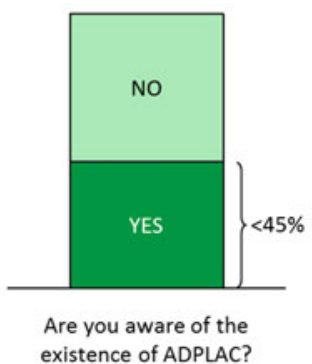

Poor linkage facilitation

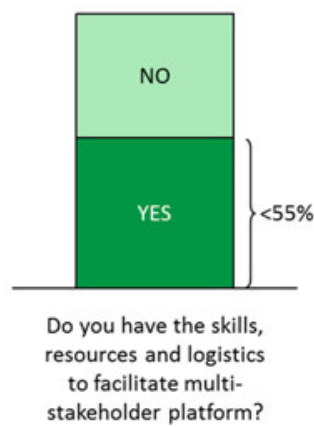

Fig. 7.4 Results from a survey among ADPLAC stakeholders in the Amhara region (Source: Demekech et al. 2010)

from Fig. 7.4 above, in the Amhara region, only about $15 \%$ of the expected agricultural development actors' linkages are strong. And less than half of the key stakeholders know about ADPLAC. The majority of the stakeholders report that they have insufficient support for linkage creation (Demekech et al. 2010).

The ADPLAC lacks a long-term strategy for systematically creating alignment across the different development actors for greater impact (MoA RCBP 2012b). The limited linkage among ATVETs, extension systems, research and higher education means that ATVETs do not receive the necessary feedback to help them adjust and deliver training and technology transfer services that are up-to-date and relevant.

The conditions framing the effectiveness of ADPLAC at the federal level seriously affect linkage activities at the lower levels. Awareness of the partners at the woreda level about the purpose and benefit of the ADPLAC is limited. This is partly due to limited efforts at the regional level in terms of providing support and organizing events on how to develop and manage linkage activities. Woreda level ADPLACs also face limitations in resources for executing linkage activities.

Apart from the ADPLAC, to overcome the chronic linkage problem in Ethiopia, many projects have also tried their own version of linkage mechanisms. Most of the time they bring together stakeholders, whom they identify as important and influential for the success of their project objectives. The JICA funded Farmers Research Group project tried to strengthen the linkage among farmers, extension agents and researchers using on-farm, adaptive, participatory research. Following this experience other subsequent project used the same approach with the same aim (MoA-Rural Capacity Building Project 2012a). The USAID/AMAREW project tried research center-based district (woreda) level innovation platforms to scale up promising technologies. There were a number of woreda linkage committee established in the project districts in Amhara region. There was some degree of success in the dissemination of technology in the project districts, but the districts were too many to handle for the research centers. And they ceased to exist as the project phased out. The ACIAR (Australian Center for International Agricultural Research)-funded, 
CIMMYT and Ethiopian counterpart-implemented conservation agriculture promotion project called SIMLESA has also come up with woreda-based, researcherfacilitated innovation platforms. There were about ten innovation platforms established in the project woredas, with two in the Amhara region.

There were operational and strategic innovation platforms in each project woreda. The operational platforms were established at the grassroots to facilitate coordinated action and joint problem-solving at local levels, while the strategic platforms focused on policy constraints and enabling environments. Establishment and operationalization of strategic platforms has been found to be difficult. However, there is some evidence that indicates that, although it is difficult to establish strategic platforms, once established, they are very effective, as they will bring top level politicians on board who are the real decision-makers in the highly hierarchical and top down Ethiopian National Agricultural Research and Extension System (NARES).

\section{Conclusions}

Generally, the Ethiopian NARES and that of the Amhara region agricultural research and extension system are characterized by large number of actors in a fragmented and underdeveloped innovation system, resulting in very low national and regional innovation capacity. The dominant thinking about the mechanism of integrating these actors, or simply about the linkage issue, continues to view research and extension as separate processes that should be organized in different organizations and can be linked linearly through periodic large assemblies and ad-hoc committees. In this view, farmers are also viewed as passive recipients of technology. As a result, research outputs do not reach farmers and remain shelved in research centers. Often, research and extension organizations compete for resources, mandates and influence rather than cooperating for a common purpose. In order to change this situation, this dominant paradigm needs to be replaced by the fact that research and extension are interlinked, overlapping and iterative processes. Hence, organization of research and extension institutes needs to take this into consideration. All past initiatives to bring about integration among these actors were projectfunded, ad hoc and not institutionalized, creating discontinuity, as well as a lack of accountability. They also lack a strong M\&E system, and are plagued by poor participation of other stakeholders, poor coordination and facilitation, poor institutional memory, and lack of clarity on the roles and responsibilities of participant stakeholders. Linkage brokering and management requires professional facilitation knowledge and skills. Such professionals are lacking and the profession not recognized. There are some successful project-based innovation platforms, but their successes were localized, not replicated and not sustainable as projects phased out. However, these experiences indicate that, in the context of a fragmented innovation system and extension systems characterized by top-down planning, strategic innovation platforms which bring together high level decision-makers could be hard to 
establish and manage sustainably, but once established and properly managed, they are ideal forms of linkage among the research and extension organizations and can easily promote region- or nationwide scaling up of proven technologies.

Open Access This chapter is distributed under the terms of the Creative Commons AttributionNoncommercial 2.5 License (http://creativecommons.org/licenses/by-nc/2.5/) which permits any noncommercial use, distribution, and reproduction in any medium, provided the original author(s) and source are credited.

The images or other third party material in this chapter are included in the work's Creative Commons license, unless indicated otherwise in the credit line; if such material is not included in the work's Creative Commons license and the respective action is not permitted by statutory regulation, users will need to obtain permission from the license holder to duplicate, adapt or reproduce the material.

\section{References}

Central Statistical Agency (2003-2011) Ethiopian agricultural sample enumeration: statistical reports on report on land utilization: private peasant holdings from 2003 to 2011. Central Statistical Agency, Addis Ababa

Demekech G, Moges F, Zeleke G, Tesfaye K, Ayalew M (2010) Multi-stakeholder linkages in rural innovation processes in the Amhara Region, Ethiopia, Working document series 137. International Centre for Development-oriented Research in Agriculture, University of Bahir Dar, Amhara Region Agricultural Research Institute and Bureau of Agriculture and Rural Development, Wageningen/Bahir Dar

FDRE (The Federal Democratic Republic of Ethiopia) (1999) Agricultural research and training project: Ethiopian research-Extension-farmer linkages strategy, vol I. FDRE, Addis Ababa

Havelock RG (1986) Linkage: a key to understanding the knowledge system. In: Beal GM, Dissanayake W, Konoshima S (eds) Knowledge generation, exchange and utilisation. Westview Press, Boulder

Kassa B (2008) Agriculturalresearch and extension linkages in Ethiopia: a historical survey. Haromaya University, Dire Dawa

Ministry of Agriculture (2014) National Crop Variety Register (2014), Issue no. 17. Federal Democratic Republic of Ethiopia, Ministry of Agriculture, Addis Ababa

MoA Rural Capacity Building Project (2012a) The performance of FREGs: costs, benefits and intervention options for improved sustainability. Haromaya University, Dire Dawa

MoA Rural Capacity Building Project (2012b) Performance of agricultural development partners' linkage advisory councils. Haromaya University, Dire Dawa

MoFED (Ministry of Finance and Economic Development) (2011) Ethiopia: building on progress. A Plan for Accelerated and Sustained Development to End Poverty (PASDEP) (2005/06-2009/ 10) Volume I: Main Text. MoFED, Addis Ababa

MoFED (2015) Federal Democratic Republic of Ethiopia. Ministry of Finance and Economic Development, 2008 fiscal year budget (Amharic). MoFED, Addis Ababa

Munyua CN, Adams PF, Thomson JS (2002) Designing effective linkages for sustainable agricultural extension information systems among developing countries in Sub-Saharan Africa. In: Proceedings of the 18th annual conference of the association for international agricultural and extension education, Durban, pp 301-307 